\title{
Religiosidade/Espiritualidade em Pacientes Oncológicos: Qualidade de Vida e Saúde
}

\author{
Silvia Aparecida Fornazari² \\ Renatha El Rafihi Ferreira \\ Universidade Estadual de Londrina
}

\begin{abstract}
RESUMO - O estudo investigou o enfrentamento religioso em 10 pacientes oncológicos de uma instituição especializada, com idades entre 25 e 55 anos. A coleta de dados deu-se por meio de entrevistas. Os resultados foram analisados considerando o conteúdo do relato verbal das participantes, assim descritos: (1) categorias de conteúdo do relato verbal (suporte emocional, cura, busca de significado, contribuições no tratamento e controle); e (2) características de religiosidade/espiritualidade. Todas as participantes apresentaram relatos verbais com conteúdos de religiosidade/espiritualidade, o que evidencia que a relação entre a doença e a possibilidade de morte fazem do enfrentamento religioso uma estratégia de redução do estresse e melhoria da qualidade de vida das participantes.
\end{abstract}

Palavras-chave: câncer; religiosidade/espiritualidade; qualidade de vida.

\section{Religiousness/Spirituality in Oncological Patientes: Life Quality and Health}

\begin{abstract}
The study investigated the religious coping in 10 cancer patients of a specialized institution, aged between 25 and 55 years old. The data were collected through interviews. The results were analyzed considering the content of the patients' verbal report, described as: (1) categories of verbal report's content (emotional support, healing, searching of meaning, contributions for treatment, and control); and (2) characteristics of religiousness/spirituality. All participants presented verbal reports with contents of religiousness/spirituality, which suggests that due to the relation between the disease and the possibility of death, religious coping became a strategy of stress reduction and quality of life improvement for those patients.
\end{abstract}

Keywords: cancer; religiousness/spirituality; quality of life.

O câncer atinge altos índices de incidência, constituindose na segunda causa de mortalidade no Brasil (Martins, 2001). $\mathrm{O}$ diagnóstico da neoplasia causa um forte impacto na vida de seus portadores (Carvalho, 2002). Para lidar com essa condição, as pessoas com câncer utilizam diferentes estratégias de enfrentamento, destacando-se no presente trabalho a religiosidade e a espiritualidade, que predominam em grande parte da população acometida por essa enfermidade (Ferreira \& Fornazari, 2007).

Folkman, Lazarus, Gruen e De Longis (1986), definem enfrentamento como "esforços cognitivos e comportamentais voltados para o manejo de exigências ou demandas internas ou externas, que são avaliadas como sobrecarga aos recursos pessoais" (p. 572). Dessa forma, muitos indivíduos utilizam estratégias de enfrentamento para lidar com determinada situação estressora. Estratégias de enfrentamento são classificadas de acordo com suas funções e podem estar focadas no problema ou na emoção. O enfrentamento focado no problema constitui-se de estratégias ativas (planejamento e solução de problemas) de aproximação em relação ao

1 Trabalho de conclusão de curso de Renatha El Rafihi Ferreira, sob orientação da Profa. Dra. Silvia Aparecida Fornazari.

2 Endereço para correspondência: Departamento de Psicologia Geral e Análise do Comportamento, Centro de Ciências Biológicas, Universidade Estadual de Londrina, Campus Universitário. Caixa Postal, 6001 Londrina, PR. CEP 86051-090. Fone/Fax (43) 3371-4227. E-mail: silfornazari@yahoo.com.br estressor. A estratégia de enfrentamento focada na emoção tem como função a regulação da resposta emocional causada pelo estressor, podendo ser representada por atitudes como a esquiva e a negação. $\mathrm{O}$ enfrentamento religioso pode estar relacionado tanto às estratégias focadas no problema quanto às estratégias focadas na emoção (Seidl, Tróccoli \& Zannon, 2001).

De forma positiva, o enfrentamento religioso está associado a estratégias de enfrentamento ativo, planejamento, reinterpretação positiva e suporte social instrumental e emocional (Seidl \& cols., 2001). Assim, a religiosidade/ espiritualidade constitui uma estratégia de enfrentamento importante diante de situações consideradas difíceis, como é o caso do diagnóstico do câncer que produz um forte impacto na vida do indivíduo e cujo tratamento é permeado de eventos estressores.

A religiosidade e a espiritualidade aparecem como importantes aliadas para as pessoas que se encontram enfermas (Fleck, Borges, Bolognesi \& Rocha, 2003). Contudo, são as consequências do enfrentamento religioso que predirão se os resultados refletidos na saúde do paciente aparecem de forma positiva ou negativa. Koenig, Pargament e Nielsen (1998) identificam estratégias positivas como aquelas que resultam em melhoras na saúde mental, redução de estresse, "crescimento espiritual" e cooperatividade. As estratégias negativas estão relacionadas com resultados que apontam correlações negativas referentes 
à qualidade de vida, depressão e saúde física, como por exemplo, uma atitude de não adesão ao tratamento por acreditar em cura divina.

A religiosidade e a espiritualidade estão recebendo cada vez mais atenção na assistência à saúde. Peres, Simão e Nasello (2007), escrevem que "o interesse sobre a espiritualidade e a religiosidade sempre existiu no curso da história humana, a despeito de diferentes épocas ou culturas. Contudo, apenas recentemente a ciência tem demonstrado interesse em investigar o tema" (p.137). Ainda nesse contexto, o Instituto Brasileiro de Geografia e Estatística - IBGE (2000) afirma que o Brasil possui um potencial religioso sincrético expressivo e alta prevalência de praticantes de religiosidade/ espiritualidade, sendo que apenas $7,3 \%$ da população não têm religião.

A relação entre espiritualidade e saúde tem se tornado um claro paradigma a ser estabelecido na prática diária do profissional de saúde. "A espiritualidade, relacionada ou não à religiosidade, historicamente tem sido ponto de satisfação e conforto para momentos diversos da vida, bem como motivo de discórdia, fanatismo e violentos confrontos" (Guimarães \& Avezum, 2007, p. 89).

$\mathrm{O}$ enfrentamento religioso abrange a religiosidade e a espiritualidade que se diferenciam em alguns aspectos. A religiosidade está relacionada com uma instituição religiosa e/ou igreja, pela qual o indivíduo segue uma crença ou prática, proposta por uma determinada religião (Lukoff, 1992; Miller, 1998). A espiritualidade é definida como característica individual que pode incluir a crença em um Deus, representando uma ligação do "Eu" com o Universo e com outras pessoas. Assim, a espiritualidade envolve questões sobre o significado e o propósito da vida, encontrando-se além da religião e da religiosidade (Sullivan, 1993).

Para Skinner (1953/1998), a religião apresenta-se como uma Agência de Controle que deriva de uma "conexão" com o sobrenatural, de forma a criar ou alterar certas contingências. De acordo com a história de reforço e punição de um indivíduo, a religiosidade/espiritualidade estará mais ou menos presente no modo como a pessoa irá vivenciar a doença. Aproximar-se dessa agência religiosa, que por meio de um ser superior que controla as contingências presentes, reforça, pune e "traz certezas" de um amanhã mais feliz, é de certa forma, "garantir" a felicidade no longo prazo.

Ainda de acordo com Skinner (1953/1998), "a obtenção do Céu ou do Inferno, diz-se, depende apenas do indivíduo. A agência controla o fiel, não pela manipulação das contingências de reforço, mas tornando certas contingências reais ou alegadas mais eficientes" (p. 387). Assim, a doença leva o ser humano a deparar-se com seus valores e com questões como a existência e a proximidade da morte. Nessa perspectiva, a religião e a espiritualidade empreendem o esforço de significar essa nova demanda apresentada para o paciente, buscando compreender a própria doença, o sofrimento, a morte e a existência (Hennezel \& Leloup, 2000).

Peres, Arantes, Lessa e Caous (2007) apontam para a existência de estudos que investigam a relação da religiosidade e/ou espiritualidade com diversos aspectos da saúde mental. Moreira-Almeida, Lotufo-Neto e Koenig (2006) descrevem que a maioria dos estudos indica que a espiritualidade e a religiosidade podem contribuir como forma de adaptação ao estresse em contextos de saúde. Peres e cols. (2007) ainda afirmam que a espiritualidade e a religiosidade são relevantes nos cuidados paliativos e relacionados à dor, como forma de tornar o atendimento totalizado ao indivíduo, pois a prática religiosa nunca deve substituir a prática médica, e sim completá-la.

A religiosidade/espiritualidade tem demonstrado grande impacto sobre a saúde física, sendo considerada como possível fator de prevenção ao desenvolvimento de doenças, e eventual redução de óbito ou impacto de diversas doenças. Estudos independentes "determinam que a prática regular de atividades religiosas tem reduzido o risco de óbito em cerca de $30 \%$ e, após ajustes para fatores de confusão, em até 25\%" (Guimarães \& Avezum, 2007, p. 93). Dessa forma, os resultados dos estudos sobre o assunto, incluindo o presente trabalho, voltam-se para a possibilidade de prevenção.

Conforme assinalado por Panzini, Rocha, Bandeira \& Fleck (2007), "o campo da qualidade de vida pode vir a se tornar um mediador entre o campo da saúde e o das questões religiosas/espirituais, facilitando o desenvolvimento de intervenções em saúde espiritualmente embasadas" (p. 113). A preocupação, enquanto profissionais da saúde, deve ser de que as pessoas enfermas sejam compreendidas em suas formas singulares de lidar com a doença, como também entender a influência dessas relações no processo de qualidade de vida desses pacientes.

O presente trabalho teve como objetivo geral investigar o enfrentamento religioso em pacientes oncológicos. Mais especificamente, objetivou-se: (a) caracterizar as participantes de acordo com suas especificidades e com a categorização do conteúdo de seus relatos verbais; (b) diferenciar o conteúdo do relato verbal das participantes quanto às características de religiosidade e espiritualidade; (c) analisar o conteúdo do relato verbal das participantes no que se refere ao comportamento de pensar sobre a morte; (d) verificar a existência de características do enfrentamento religioso que facilitam e/ou dificultam a qualidade de vida de pessoas com câncer.

\section{Método}

\section{Participantes}

Dez pacientes oncológicos, da Associação Voluntária do Câncer de Assis - SP, com idades entre 25 e 55 anos, englobando nível socioeconômico diversificado participaram deste estudo. A seleção foi realizada aleatoriamente, considerando os pacientes que estavam sendo atendidos pela Associação Voluntária do Câncer de Assis - SP, no momento em que a pesquisa foi realizada. Todos aqueles que estavam em tratamento e aceitaram participar foram entrevistados. A amostra constitui-se de $100 \%$ de participantes do sexo feminino, porque os poucos homens que frequentavam a instituição não quiseram participar do estudo. As participantes receberam todas as informações cabíveis sobre a pesquisa e assinaram o Termo de Consentimento Livre e Esclarecido. 


\section{Instrumento}

Para a coleta de dados, foi utilizado um roteiro de entrevista, que visava obter o conteúdo do relato de história de vida das participantes em relação a aspectos específicos relevantes para a pesquisa. As seguintes informações constavam no roteiro: data da entrevista, entrevistadora, entrevistado, sexo, idade, escolaridade, tempo de diagnóstico, tipo de câncer, tratamento e religião. A seguir as seguintes questões eram levantadas: (1) O que a fé representa para você?, (2) A fé influenciou em relação à sua doença? Como?, e (3) Fale a respeito de suas experiências com relação à fé.

\section{Procedimento}

As entrevistas foram realizadas, por escolha das participantes, em suas respectivas residências. As entrevistas foram gravadas em fita cassete e outras manifestações gestuais e expressivas foram anotadas pelo pesquisador. Então, os relatos das participantes foram transcritos e analisados.

\section{Análise de dados}

A análise dos dados foi realizada a partir do conteúdo do relato verbal das participantes, presente nas entrevistas. Compreendeu repetidas leituras, seleção das verbalizações que continham argumentos referentes ao interesse da pesquisa, e análise do conteúdo do relato verbal (Marins, 1996). As leituras repetitivas almejaram revelar a complexidade das manifestações das participantes.

Com o objetivo de garantir a fidedignidade dos dados, um segundo pesquisador participou da análise dos conteúdos dos relatos verbais das participantes. Cada pesquisador ouviu a entrevista repetidas vezes, identificando o conteúdo expresso por seu relato, e categorizando-o. Após o trabalho individual dos pesquisadores, os dados foram comparados e as categorias que haviam sido levantadas por cada pesquisador foram discutidas de acordo com os objetivos da pesquisa. Para a presente análise, foram descritas as categorias que os pesquisadores concordaram estarem presentes no conteúdo do relato verbal das participantes (Marins, 1996).

As características de religiosidade e espiritualidade presentes no conteúdo do relato verbal das participantes foram diferenciadas e registradas de acordo com suas definições. O conteúdo relacionado ao comportamento de pensar sobre a morte também foi analisado.

\section{Resultados e Discussão}

Inicialmente foi realizada a caracterização da amostra, sendo os resultados divididos em: (1) Categorias levantadas a partir do conteúdo do relato verbal das participantes; (2) Características de religiosidade e espiritualidade.

De acordo com a caracterização da amostra, a presente pesquisa compreendeu seis elementos: idade, gênero, escolaridade, tempo de diagnóstico, tratamento e religião. Embora o instrumento utilizado incluísse a informação sobre o tipo de câncer, a maioria das participantes não soube nomear o diagnóstico com precisão, apenas remetendo-se ao local onde a doença se instalara e, por isso, esse dado não foi considerado.

Quanto à idade das participantes, 20\% da amostra apresentavam idades entre 25 e 35 anos, $30 \%$ da amostra, entre 35 e 45 anos, e $50 \%$ da amostra, entre 45 e 55 anos.

O fato da amostra constituir-se de $100 \%$ de participantes do sexo feminino pode indicar que homens e mulheres têm modos diferentes de enfrentamento da doença, incluindo até a possibilidade de que os homens solicitem ajuda à Associação com menor frequência do que as mulheres. Tal questão sugere que as mulheres utilizam mais do que os homens estratégias de apoio social. A literatura aponta que o homem apresenta mais dificuldade de se aproximar de meios de suporte social, uma vez que limita seus contatos a familiares e pessoas envolvidas no tratamento (Gianini, 2007).

Com relação ao tempo de diagnóstico, 30\% da amostra souberam do diagnóstico entre 1 e 2 anos; $40 \%$, entre 2 e 4 anos e $30 \%$, entre 4 e 7 anos. Finalmente, com relação ao tipo de tratamento, foi observado que o tratamento inclui apenas quimioterapia para $20 \%$, quimioterapia acompanhada da radioterapia para $20 \%$, quimioterapia e medicação para $30 \%$, e quimioterapia, radioterapia e medicação para $30 \%$ da amostra. Assim, a quimioterapia está presente como forma de tratamento para todas as participantes.

Todas as participantes relataram possuir uma "ligação" com um "ser supremo". Assim, as religiões aparecem de forma diversificada, predominando o cristianismo (60\%) - dividindo-se entre a religião católica (40\%) e evangélica $(20 \%)$ - e a religião budista (10\%). As demais participantes (30\%) relataram acreditar em Deus, mas sem a mediação de uma instituição religiosa, o que caracteriza a espiritualidade. Todas as participantes referiram possuir a crença antes de receber o diagnóstico, porém se aprofundaram e se apegaram a esta de forma mais assídua após o diagnóstico.

\section{Categorias levantadas a partir do conteúdo do relato verbal das participantes}

$\mathrm{Na}$ presente amostra, observa-se, a partir do conteúdo do relato verbal de todas as participantes, a presença do enfrentamento religioso, demonstrada a partir de relatos que continham referências a um "Deus" ou a um "ser supremo". O conteúdo desses relatos aponta para o uso de estratégias, onde foi possível levantar cinco categorias: Suporte Emocional, Cura (transformação de vida), Busca de Significado, Contribuições no Tratamento e Controle.

A Busca de Significados apareceu em 80\% das participantes e o Suporte Emocional, em 70\% delas, sendo estas as categorias que mais se destacaram nos relatos das participantes. Tal fato pode demonstrar que a religiosidade e/ou espiritualidade proporcionam um forte auxílio tanto no acolhimento como na procura por significação, aparecendo como variáveis importantes para o enfrentamento da problemática. Esse fator demonstra o quanto o indivíduo precisa buscar uma explicação para os eventos que o cercam e até mesmo para seu futuro no longo prazo, além do quanto essa estratégia pode ajudá-lo a enfrentar a situação atual que vivencia. Grande parte das participantes $(60 \%)$ atribuiu à religiosidade 
e à espiritualidade a causa de sua Cura (transformação de vida) e/ou Contribuições no Tratamento, o que sugere que designam a um "ser supremo" e/ou transcendental o motivo de uma possibilidade de cura ou melhora.

A Figura 1 mostra a frequência de conteúdos, presentes nos relatos verbais de todas as participantes, relacionados a cada uma das categorias.

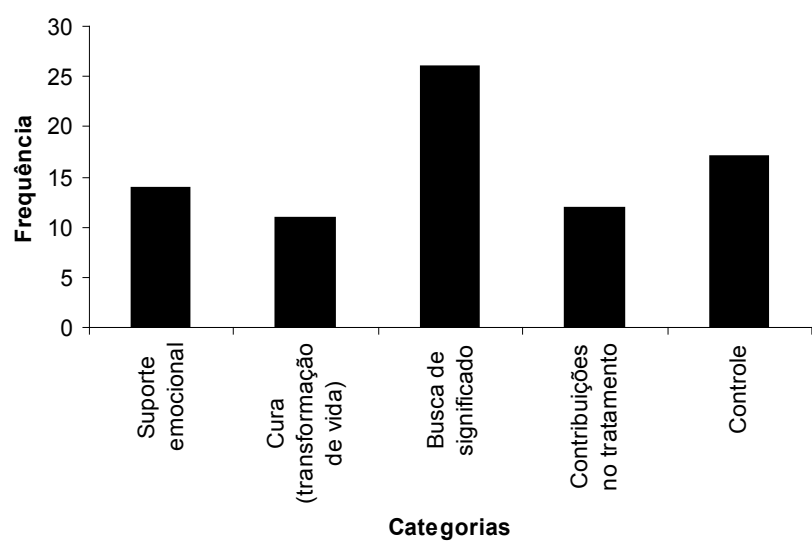

Figura 1. Freqüência de conteúdos, presentes nos relatos verbais de todas as participantes, referentes à cada categoria.

É interessante notar em alguns relatos que se encontram nas categorias Cura (transformação de vida) e Contribuições no Tratamento, que algumas participantes referem-se a um "encontro" com um ser supremo, e a esse "encontro" atribuem a melhora do tratamento e a cura. Isso pode ser observado no conteúdo dos relatos abaixo:

Então aquele assopro que senti, para mim foi Jesus que passou na minha vida. E me deu mais uma oportunidade de viver melhor (P5).

Lembro-me de que na primeira noite, quando estava no hospital, recuperando-me da cirurgia, vi-me de repente, sorrindo sem saber para quem... Não foi sonho, nem delírio. Estava bem desperta e consciente. Uma presença que eu não via, mas sentia, inundou meu ser e me trouxe uma sensação de leveza, de bem estar, de conforto e de confiança (P9).

As categorias Cura e Contribuições no Tratamento estão intimamente relacionadas à categoria Controle. Embora presentes em apenas 30\% das participantes, o número de relatos referentes à categoria Controle foi grande (17 relatos; ver Figura 1), demonstrando a relevância dessa categoria no conteúdo do relato verbal das participantes. Abaixo estão apresentados alguns exemplos dessa categoria:

Hoje a minha vida não pertence mais a mim. E sim a meu Pai que sabe de todas as coisas. Hoje se quero alguma coisa eu coloco nas mãos de Deus. Porque Ele que sabe o que é bom pra cada um de nós. E se não for do jeito que eu queria, eu não me lamento (P4).

A diferença de hoje é que eu penso assim. Nós enxergamos até a janela, mas Deus enxerga além da janela. Por isso eu entrego tudo nas mãos Dele, pois sei que Ele só quer o meu melhor (P4).
Mas sei lá, como vou morrer só Deus que sabe (P8).

Posso até morrer com essa doença ou as sequelas dela, mas enquanto Ele quiser estarei aqui (P10).

É loucura para o homem entender a vontade do Pai em nossas vidas, por isso não me preocupo em entender o que Deus quer com a permissão dessa doença no meu corpo, mas Ele sabe de todas as coisas (P10).

A partir da análise realizada, pode-se inferir que a possibilidade de controle sobre as próprias vidas é fundamental. Quando o sujeito tem controle sobre as contingências presentes em sua vida, ele lida com os acontecimentos de modo mais tranquilo; por outro lado, aquilo sobre o que não se tem controle é fonte de ansiedade e preocupação. Aguardar que os acontecimentos tomem seu curso, sem ter o que fazer para contribuir, é muitas vezes, um complicador na história dos indivíduos. A religiosidade contribui com a ideia de que existe alguém maior, responsável por esse controle, e ainda, alguém que deseja o melhor para a pessoa. Acreditar e colocar o controle nas mãos de Deus é, dessa forma, um fator que reduz o estresse e a ansiedade.

Por meio dessas categorias, levantadas a partir do conteúdo do relato verbal, pode-se notar que as participantes atribuem características ao enfrentamento religioso que consideram positivas, ou seja, responsáveis por uma melhoria em sua qualidade de vida. O termo qualidade de vida neste estudo adota como critério o que Koenig e cols. (1998) citam como características positivas do enfrentamento religioso, referindo-se à cooperatividade, "crescimento espiritual", redução de estressores e melhoras na saúde mental.

\section{Características de religiosidade e espiritualidade}

A Figura 2 representa a frequência de conteúdos, incluídos nos relatos verbais de cada participante, referentes à Religiosidade e Espiritualidade.

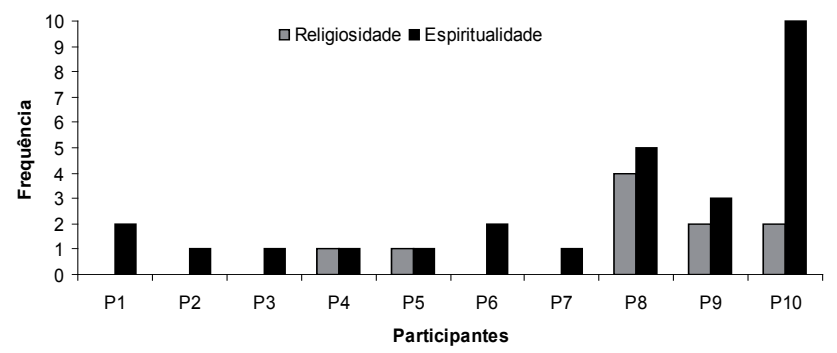

Figura 2. Frequência de conteúdos, presentes nos relatos verbais de cada participante, referentes à Religiosidade e Espiritualidade.

A presente amostra revelou que $100 \%$ das participantes apresentaram características de espiritualidade em seus relatos e 50\% dessas demonstraram características de religiosidade em suas falas. Pode-se perceber que a espiritualidade aparece em alto índice nos relatos, chegando a $80 \%$ em P10. A representação da espiritualidade como uma busca individual de significados de vida, bem como uma relação com o ser supremo (Koenig, 2001), revela que a espiritualidade abrange 
qualquer tipo de religiosidade, o que pode ser demonstrado no presente estudo, onde todas as participantes apresentam relatos de espiritualidade, embora $50 \%$ não tenham relatado religiosidade.

Os relatos de espiritualidade referem-se a um ser transcendente, e a uma busca por significação, conteúdos esses presentes nos relatos categorizados como Busca de Significado.

Hoje eu acredito mais na existência de um ser superior, que não é carrasco como muitas religiões impõem, mas nos coloca desafios a serem vencidos para nosso crescimento pessoal e espiritual (P1).

A fé para mim representa Deus, o ser superior, a força que vem do Universo (P3).

Os conteúdos dos relatos acima estão mais relacionados a uma busca individual por um ser supremo. Podem ser compreendidos a partir do que Peres e cols. (2007) descrevem: "espiritualidade pode ser definida como aquilo que traz significado e propósito à vida das pessoas. A espiritualidade é reconhecida como um fator que contribui para a saúde e a qualidade de vida de muitas pessoas" (p. 84).

Não se encontra como características do conteúdo desses relatos uma ligação mediada por uma instituição de cunho religioso, um dos elementos que difere a espiritualidade da religiosidade.

Em termos de religiosidade, os relatos verbais indicam a participação em uma instituição religiosa e uma comunidade, que podem ser observadas nos exemplos a seguir:

Hoje eu sou Católica, Apostólica, Romana, Militante (P4).

Mais eu tenho dentro da minha religião... (P8).

Primeiro quero falar que eu sou Católica Apostólica Romana Praticante (P8).

Essas falas parecem sugerir que pertencer a um núcleo, centro ou igreja revela a importância da religiosidade para essas participantes.

As práticas adotadas por uma determinada religião também estão demonstradas quando os relatos apontam a busca por um líder e rigorosidade nas orações como manifestações de fé e busca por conforto, dever e devoção.

Eu rezo o terço todo dia (P8).

Daí minha necessidade da oração, da meditação, da leitura religiosa e da frequência à igreja, para alimentar e sustentar a minha fé (P9).

Oro, mesmo com pouco ânimo, para que Deus reavive a minha crença (P9).

Foi quando chamamos o pastor da igreja, e ele impondo as mãos... no dia seguinte amanheceram (os filhos) bem melhor e em seguida ganharam alta e viemos pra casa com a Graça de Deus... (P10).
Orei com um missionário pela TV, e fui curada na hora, está normal o meu joelho para a honra e a glória de Deus. Faço minha oração de joelhos por longo período sem sentir nada... (P10).

E Deus na minha Igreja, eu faço parte da Igreja (X). E tenho o Padre (Y) como meu confessor, meu amigo e meu orientador espiritual. E sou ministra de eucaristia, sou catequista, sou coordenadora do meu setor, faço grupos de oração, eu vejo momentos fortes dentro da minha comunidade (P8).

Os dados de religião revelaram que a maioria da amostra pertence ao cristianismo (católicas e evangélicas). Além disso, as que afirmaram ser espiritualizadas e acreditar em Deus, mas sem ter uma ligação intermediada por uma religião, demonstraram características mais ligadas às crenças cristãs. Greschat (2005) afirma que os cristãos têm a oração como forma de se comunicar com "Deus", referindo-se à existência de um diálogo entre um "Eu" e um "Tu".

A oração é definida por Greschat (2005) como a "comunicação viva do devoto com um Deus imaginado como pessoal e experimentado como presente, uma comunicação que reflete as formas das relações humanas sociais" (p. 147).

As orações, devoções e busca por um líder, referidas nos relatos, constituem-se em elementos da religiosidade, funcionando como práticas adotadas por uma determinada religião, o que confere um dever e uma possível "salvação" e confiança. Esta confiança também é bastante observada na categoria Controle, aparecendo como uma importante aliada para a redução da ansiedade.

O câncer na sociedade ocidental é carregado de muitos estigmas, estando relacionado à dor, ao medo e à diversas formas de perdas: da produtividade, do atrativo sexual, do corpo etc (Chiattone, 1992). A sociedade ocidental, em sua história ontogenética, vem estabelecendo, por meio de agências de controle, modelos e padrões culturais que acabam atingindo também o comportamento dos cidadãos no contexto de saúde. As agências religiosas exercem grande influência nesse contexto por serem "possuidoras" do saber no longo prazo, ou seja, do saber "após a morte", e por buscarem uma significação que explique os mistérios e os eventos que nos deparamos em vida. Esse controle pode gerar dois efeitos conflitantes: culpa pelos erros e "pecados" e medo de um amanhã infeliz; e busca de significação para a vida e a morte, podendo levar ao conforto de um amanhã feliz. Em momentos de fragilização, de doença, de dor, o enfrentamento religioso é utilizado como fonte de conforto proporcionando um controle que vai além do humano; no momento em que o paciente atribui esse controle a um ser supremo, ele se "liberta", reduzindo assim sua ansiedade e medo. No conteúdo do relato abaixo, pode-se perceber essa entrega.

Foi ai que entrou a mão de Deus, Ele age quando não temos mais o controle da situação (P10).

Para Hennezel e Leloup (2000), a imagem que o ser humano possui da morte, é fruto de uma herança cultural, de uma civilização ou de uma religião, onde o homem corresponde a tal representação. Pode-se dizer que essa imagem construída está relacionada com os valores que foram empregados na história de reforço e punição do indivíduo, onde a 
agência religiosa apresenta um papel mediador, exercendo assim seu controle.

O câncer como uma doença estigmatizada, traz a ideia de morte e sofrimento e isso acaba criando barreiras à prevenção (Chiattone, 1992). O profissional que trabalha com pacientes oncológicos deve estar atento aos seus próprios estigmas, suas próprias dificuldades de lidar com a fragilidade humana e com suas próprias fragilidades.

Nessa amostra, notou-se, nos relatos verbais das participantes, conteúdos relacionados a um futuro no longo prazo, revelando que a doença pode lhes aproximar desse amanhã desconhecido, e que esse amanhã só depende da vontade de um ser supremo.

Mais sei lá, como vou morrer só Deus que sabe (P8).

Mas agora eu vivo assim, o que passou, o que vem só Deus sabe (P8).

E Deus quer sempre o melhor para voce, sempre o melhor, então se eu tenho essa doença agora no meu caminho, e se Ele achar que para mim o melhor é eu me curar, ele vai me dar a cura. Se Ele achar que é melhor eu estar indo lá ... para mim né (emoção) (P8).

A única preocupação que eu coloco para Ele são as minhas filhas, mais se Ele me levar, é porque Ele vai estar dando todo o necessário para que elas caminhem sem mim, né (P8).

Posso até morrer com essa doença ou as sequelas dela, mas enquanto Ele quiser estarei aqui (P10).

Deus tem um plano na minha vida, ou então já teria me levado (P10).

Assim, a doença leva o ser humano a deparar-se com seus valores e com questões como a existência e a proximidade da morte. Nessa perspectiva, a religião e a espiritualidade empreendem o esforço de significar essa nova demanda apresentada para o paciente, buscando compreender a própria doença, o sofrimento, a morte e a existência (Hennezel \& Leloup, 2000). No presente estudo, a categoria Busca de Significado demonstrou essa preocupação por parte das participantes que utilizam a religiosidade/espiritualidade como elemento facilitador de enfrentamento. O relato abaixo exemplifica o que aqui foi mencionado.

A fé representa a esperança em um amanhã melhor, de uma vida após a morte, de seres humanos melhores e sempre em aperfeiçoamento (P1).

\section{Considerações Finais}

O enfrentamento religioso configura-se em estratégias cognitivas ou comportamentais que utilizam da fé, da religiosidade e da espiritualidade para enfrentar eventos estressores (Faria \& Seidl, 2006). De acordo com Moreira-Almeida e cols. (2006), a religiosidade/espiritualidade relacionada à saúde tem sido cada vez mais investigada e as evidências têm apontado para uma relação habitualmente positiva entre indicadores de envolvimento religioso e de saúde mental.

Os resultados obtidos neste estudo demonstram que o paciente oncológico deve ser compreendido em sua totalidade, e que seus aspectos religiosos/espirituais devem ser considerados, para que ele seja respeitado em sua singularidade bem como em suas crenças e valores. Cabe destacar que o enfrentamento religioso pode apresentar-se como elemento que contribui na adesão ao tratamento, no enfrentamento da problemática, na redução do estresse e ansiedade, e na busca de significado para sua atual situação. Respeitar a crença do indivíduo, e considerá-la, contribui também para uma melhor relação equipe profissional-paciente.

$\mathrm{O}$ indivíduo tem o direito de ter qualidade de vida até seu último momento de existência. Até mesmo no momento da morte, os profissionais devem atentar-se a maneiras de reduzir a ansiedade e o sofrimento, e a espiritualidade/ religiosidade pode contribuir como uma importante aliada nesse momento.

O paciente não deve ser considerado apenas como um corpo doente, mas como um indivíduo que carrega consigo uma história constituída pela interação entre fatores biológicos e ambientais. A equipe profissional que procura manter uma atitude aberta a todos esses aspectos, posiciona-se de forma a não reduzir o paciente a um corpo em sofrimento, criando assim a possibilidade de um novo espaço significativo nessa relação entre paciente e profissional.

De acordo com Moreira-Almeida e cols. (2006), "há evidências suficientes disponíveis para se afirmar que o envolvimento religioso habitualmente está associado à melhor saúde mental" (p. 242). A presente pesquisa nos fornece indícios que relacionam o enfrentamento religioso (religiosidade e espiritualidade) com o processo de qualidade de vida de pessoas com câncer, trazendo evidências sobre a possibilidade de que a fé possa influenciar positivamente na saúde e qualidade de vida dessas pacientes. Pois de acordo com Koenig e cols. (1998), as estratégias de enfrentamento religioso são positivas quando resultam em melhoras na saúde mental, redução de estresse e adesão ao tratamento, o que se verifica no conteúdo dos relatos verbais das participantes.

Este estudo abriu espaço para importantes aspectos presentes na relação do câncer com a espiritualidade/religiosidade, considerando que conteúdos como a morte foram relevantes na presente amostra. A partir deste estudo, cria-se, também, possibilidades para novas pesquisas que apontem para a necessidade de capacitação de profissionais preparados para lidar com temas como a religiosidade/espiritualidade e a existência/morte. $\mathrm{O}$ estudo ainda traz uma contribuição no sentido de informação e conhecimento válidos para propostas preventivas.

\section{Referências}

Carvalho, M. M. (2002). Psico-oncologia: história, características e desafios. Psicologia. USP, 13, 151-166.

Chiattone, H. B. (1992). Uma vida para o câncer. Em V. Angerami-Camon, (Org.), O doente, a psicologia e o hospital (pp. 71-108). São Paulo: Pioneira. 
Faria, J. B., \& Seidl, E.M. F. (2006). Religiosidade, enfrentamento e bem-estar subjetivo em pessoas vivendo com HIV/AIDS. Psicologia em Estudo, 11, 155-164.

Ferreira, R. E. R., \& Fornazari, S. A. (2007). A influência da fé na qualidade de vida em pacientes oncológicos. Relatório Final de Trabalho de Conclusão de Curso, Universidade Paulista, Assis.

Fleck, M. P. A., Borges, Z. N., Bolognesi, G., \& Rocha, N. S. (2003). Desenvolvimento do WHOQOL, módulo espiritualidade, religiosidade e crenças pessoais. Revista Saúde Pública, 37, 446455.

Folkman, S., Lazarus, R. S., Gruen, R. J., \& De Longis, A. (1986). Appraisal, coping, health status and psychological symptoms. Journal of Personality and Social Psychology, 50, 571-579.

Gianini, M. M. S. (2007). Câncer e gênero: enfrentamento da doença. Dissertação de Mestrado, Pontifícia Universidade Católica de São Paulo, São Paulo.

Greschat, H. J. (2005). O que é ciência da religião?. São Paulo: Paulinas.

Guimarães, H., P., \& Avezum, A. (2007). O impacto da espiritualidade na saúde física. Revista Psiquiatria Clínica, 34, 88-94.

Hennezel, M., \& Leloup, J. Y. (2000). A arte de morrer. Petrópolis: Editora Vozes.

Instituto Brasileiro de Geografia e Estatística - IBGE (2000). Censo demográfico. Retirado em 25/07/2005, de http://www.ibge. gov.br.

Koenig, H. (2001). Handbook of religion and health: A century of research reviewed. Oxford: University Press.

Koenig, H. G., Pargament, K. I., \& Nielsen, J. (1998). Religious coping and health status in medically ill hospitalized older adults. The Journal of Nervous and Mental Disease, 186, 513-521.

Lukoff, D. (1992). Toward a more culturally sensitive DSM-IV (psychoreligious and psychospiritual problems). The Journal of Nervous and Mental Disease, 180, 673-682.

Marins, S. C. F. (1996). As possibilidades profissionais dos portadores de deficiência mental, de acordo com o enfoque dos pais. Dissertação de Mestrado, Universidade Federal de São Carlos, São Carlos.
Martins, P. S. (2001). Barreiras psicológicas à prevenção do câncer: uma discussão analítico comportamental. Em H. J. Guilhardi, (Org.), Sobre comportamento e cognição: expondo a variabilidade (pp. 305-315), Santo André: ESETec.

Miller, W. R. (1998). Researching the spiritual dimensions of alcohol and other drug problems. Addiction, 93, 979-990.

Moreira-Almeida, A., Lotufo-Neto, F., \& Koenig, H. G. (2006). Religiousness and mental health: A review. Revista Brasileira de Psiquiatria, 28, 242-250.

Panzini, R. G., Rocha, N. S., Bandeira, D. R., \& Fleck, M. P. A. (2007). Qualidade de vida e espiritualidade. Revista Psiquiatria Clínica, 34, 105-115.

Peres, M. F. P., Arantes, A. C. L. Q., Lessa, P. S., \& Caous, C. A. (2007). A importância da integração da espiritualidade e da religiosidade no manejo da dor e dos cuidados paliativos. Revista Psiquiatria Clínica, 34, 82-87.

Peres, J. F. P., Simão, M. J., \& Nasello, A. G. (2007). Espiritualidade, religiosidade e psicoterapia. Revista Psiquiatria Clínica, 34, 136-145.

Seidl, E. M. F., Tróccoli, B. T., \& Zannon, C. M. L. C. (2001) Análise fatorial de uma medida de estratégias de enfrentamento. Psicologia: Teoria e Pesquisa, 17, 225-234.

Sullivan, W. P. (1993). It helps me to be a whole person: The role of spirituality among the mentally challenged. Psychosocial Rehabilitation Journal, 16,125-134.

Skinner, B. F. (1998). Ciência e comportamento humano (J. C. Todorov e R. Azzi, Trads.). São Paulo: Martins Fontes. (Trabalho original publicado em 1953)

Recebido em 19.12.2007

Primeira decisão editorial em 24.06.2008

Versão final em 19.05.2010

Aceito em 19.05.2010 